\title{
DERS DENETIMI
}

\section{Doç. Dr. Haydar TAYMAZ*}

Eğitim etkinliklerinin temel öğesi olan öğretmenin hergün gelişmekte olan teknoloji, çoğalan sosyo-ekonomik sorunlar, çağın getirdiği yenilikler karşısında başarılı olabilmesi ve sürdürebilmesi için sürekli olarak geliştirilmesi ve desteklenmesi gerekmektedir. Öğretmene yapılan yardım kuşkusuz öğrenciye yansımaktadır. Ĕgitim sisteminde öğretmene yardım edilebilmesi için hangi tür yardima ihtiyacı olduğunun saptanması, onun için de çalışmalarının. izlenmesi ve denetlenmesi zorunludur.

Ders denetimi, bir öğretim kurumunda, öğretmenin öğrenci ile karşıkarşıya bulunduğu ve öğretim yaptığı sırada davranışlarının gözlenmesi, ders öncesi ve sonrası etkinliklerinin incelenmesi ve değerlendirilmesi için yapılan denetimdir.

Teknik denetim olarak nitelendirilen ders denetimi, öğretmenin öğretim yapma ve ders vermedeki başarısını değerlendirmenin yanısıra, yeteneklerinin geliştirilmesi, mesleğe ve çevreye uyumunun sağlanması, yenlik ve gelişmelerin tanıtılması, mesleki yardımda bulunulması, eksiklik ve hatalarının saptanarak giderilmesi ve geliştirilmesini amaçlar.

Ders denetimi okullarda genel denetim sirasinda veya bunlarayrı olarak yapılan, öğretmenin kendi alanındaki yetişkinliğini ve çalışmasını inceleyip değerlendirmeye yönelik bir denetim türüdür. Ayrıca öğretmenin sicil amirleri tarafından ortaklaşa doldurulan sicil raporlarında değerlendirme sonucu yetersiz olarak belirlendikleri veya bakanlik müfettişlerinin denetimleri sonunda yetersiz bulup tekrar denetlenmesini önerdikleri öğretmenin branş müfettişi tarafindan tekrar denetlenmesini öngören ve bakanlık onayına dayalı olarak yapılan denetime, mucipli ders teftişi denir.

* Eğitim Yönetimi ve Planlaması Bölümü 
Ders Denetiminin Amaçları

Ders denetimi, eğitimin saptanmış hedeflerine, ulaşmak için öğretim ve öğrenim etkinliklerinin oluşumunu gözlemek üzere dershane, laboratuar ve atelyelerde yapilır. Ayrica bu yerlerdeki gözlem dışında öğretmenin yaptığı öğretime hazırlık ve tamamlayıcısı durumunda olan ders dı̧ı etkinlikleri de incelenir. Ders denetiminin amaçları denetimin genel amaçları içinde yer alır ve aşağıdaki şekilde sıralanabilir.

1. Öğretmenin özellikle iyi ve ümit verici karakteristiklerini saptamak.

2. Öğretmeninin öğretimdeki eksik yönlerini belirlemek, giderici önerilerde bulunmak.

3. Öğretmenleri görevlerini en iyi bir şekilde yapmaya özendirmek ve güdülemek. olmak.

4. Okulda yapılan öğretimde birlik sağlamak üzere yardımcs

5. Okulda öğretmenlerin uyguladıkları öğretim metotlarını geliştirmek.

6. Öğretim araçlarının sağlanması ve kullanılmasında yardımcı olmak.

7. Öğrenci başarısının bilimsel yöntemlerle ölçülmesi ve değerlendirilmesinde yardım etmek.

8. Öğretmenin karşılaştığı sorunları çözümlemede yol göstermek.

9. Öğıtmenlere yapılan yardımlarla denetim etkinliklerine güvenlerini artirmak.

10. Öğretmenin öğretimdeki başarısını değerlendirmek ve rapor hazırlamak.

Ders Denetiminde Kaşılaşılan Sorunlar.

Ders denetimi öğretimin etkililik derecesini, öğrencilerin yetiştirilmesinde yararlanılan kaynakları gözlemek ve gelişmeyi sağlamak amacı ile yapılır. Ancak denetim sırasında gözlenen öğretmen davranışı olduğundan, öğretmenin değerlendirilmesi ile sonuçlanır. Ders denetimlerinde karşılaşilan sorunlar, teftişin genel sorunlarından soyutlanamaz. Öğretmenlerin ders denetimlerinde karşılaşılan sorunlar aşağıdaki şekilde özetlenebilir. 
1. Öğretmenler ders denetiminin hangi ölçütlere göre yapildığı ve değerlendirildiğini tam olarak bilmemektedirler.

2. Değerlendirmelerde açıklık ilkesine tam uyulmadığından öğretmenler denetim sonuçlarını, dolayısiyle olumlu ve olumsuz bulunan yönlerini öğrenememektedirler.

3. Ders denetimi yolu ile yapılan değerlendirmeler öğretmenlerin yetiştirilmeșinde ve geliştirilmesinde fazla etkili olamamıştır.

4. Ders denetimi yolu ile yapılan değerlendirmelerde, başarının objektif olarak ölçülmediği kanısı yaygındır.

5. Ders denetimleri için ayrilan süre, öğretmenleri çeşitli yönleri ile tanıyıp değerlendirmeye yetmemektedir.

6. Ders denetimi yapan müfettişler öğretmenlere beklenen rehbelik ve güdülemede bulunamamaktadırlar.

7. Öğretmenler müfettişlerin geneldeki tutum ve davranışlarından hoşnut değildirler.

8. Müfettişlerin öğretmenleri değerlendirirlerken okul müdürünün etkisi altında kaldıkları genel bir kanıdır.

9. Ders denetiminde hata ve eksikliklerin giderilmesi için önelemler önerilmesi yerine raporlanması yoluna gidilmektedir.

10. Ders denetimlerinde süreklilik sağlanamamakta, uzun yıllar ders denetimi görmeyen öğretmenler çoğunluktadur.

Ders Denetiminde Dikkat Edilecek Hususlar

Denetimin bir eğitimsel rehberlik biçimini alması ve bunun gereklerinin yerine getirilmesi kuşkusuz bazı hususların gözönünde bulundurulmasını gerektirir. Ders denetiminin amaçlarına ulaşılabilmesi için aşağıda sıralanan genel kurullara uyulması gerekir.

1. Ders denetimi önceden planlanmalidır. Denetim yolu ile kurum ve öğretmenin planlı çalışmaları izlenediğinde, diğer bir deyişle yapılan çalş̧maların plana uygunluğu denetlendiğine göre denetimin daha iyi ve örnek olabilecek biçimde planlanmış olması gerekir. Denetim planı, yapılacak denetimin amaçlanı, denetlenecek öğretmenleri, dersleri, zaman ve süreleri kapsamına alır.

2. Ders denetiminden önce müfettiş dersine gireceği öğretmenle görüşmelidir. $\mathrm{Bu}$ görüşme müfettiş ve öğretmenin birbirlerini tanımalarını sağlayacak, bir nezaket kuralı yerine getirilmiş olacak, müfettişin rehberlik yapmasını kolaylaştıracaktır. Görüşme sırasında 
öğretmenin hangi dersine ne zaman gireceği ve hangi konunun öğretimi izleneceği belirlenir.

3. Ders denetiminden önce yöneticilerden öğretmen hakkında bilgi alınmalıdır. Orta dereceli öğretim kurumlarında ders denetiminden önce okul müdüründen öğretmen hakkında bilgi ve kanaatlarını kapsayan bir formun doldurulması istenmektedir. Öğretmenin çeşitli yönlerden içinde bulunduğu ortam başarısını olumlu veya olumsuz yönde etkiliyebilecek, ders denetiminin yapıldığı süre içinde verilecek karar öğretmen hakkındaki değerlendirmenin objektifliğini zedeliyecektir. Bu form ve müdürün kanaatleri öğretmeni değerlendiren müfettişi bağlamaz, ancak kendisine yardımcı olur.

4. Ders denetimi için nezaman girileceği önceden duyurulmalıdır. Öğretmenin öğretimdeki başarısı, görev gereklerini yerine getirebilme, kuralları uygulayabilme ve caba sarfetme derecesine bağlıdır. Ders denetimi kontroldan öte, rehberlik gerektirir. Kontrolu gerektiren özel durumlar dişında öğretmeni denetim için habersiz ce yakalama görüşü yarar sağlamaz.

5. Müfettiş dershaneye öğretmenle birlikte girmelidir. Müfettişin öğretmenle birlikte derse girmesi, öğretmenin öğrencilerine müfettişi tanıtma, sinıfta bulunacağını belirtme, öğretime başlama hazırlığını yapma imkanı verecektir. Öğretmen derse başladıktan sonra müfettişin dershaneye girmesi halinde, öğretim etkinliği düzensiz olarak bölünecek, öğrenciler beklenmedik bir ziyaretci ile karşılaşacak, biı baskın havası yaratılacak, korku ve kuşku yeralacaktır. Aslında öğretmenle birlikte dershaneye girilmediğinde öğretmenin derse başla ile ilgili davranışlanı gözlenemiyecektir.

6. Müfettiş özel durumlarda öğretmenden sonra derse girmelidir. Öğretmenin proğram ve günlük planları dışına çıkan ders içi içi etkinliklerinde bulunduğu, gerekli öğretimi yapmadığı, öğretim süresini değerlendirmediği gibi şikayet veya ihbarlarin olması halinde ders denetimi kontrol niteliğinde yapılabilir. Bu durumda dershaneye kapının çalınarak girilmesi tartı̧̧ma konusu olmakla birlikte, en azından gelenek ve nezaket kuralı gereği, kapının çalınması önerilir. Habersiz ve yalnız derse giren müfettiş öğretmen ve öğrencilere kendini tanıtmalı, öğretmenin öğretime normal koşullarda devamını sağlamalıdır.

7. Müfettiş öğretmen ve öğrencileri izliyebileceği bir yere oturmalıdır. Ders denetimi sırasında öğretim ve öğrencilerin öğrenim 
etkinliklerinin gözlenebilmesi için normal dersanelerde; dershanenin yan ortalarında bir yer seçmeli, öğrencilerin gereksiz dikkat ve ilgilerini çekici davranışlar göstermeksizin gözlemde bulunmalıdır.

8. Müfettiş denetim sırasında sınffin bir üyesi gibi davranmalıdır. Denetim sırasında öğrencinin dikkat ve ilgisini çekecek davranışlardan kaçınmalı, bakışları yalnız öğretmen veya belirli öğrenciler üzerinde tutulmamal, öğretmen hakkında not tutulduğu hissettirilmemelidir, Müfettiş sınıfın bir üyesi olarak öğrenciler arasındayer almalı, ders ortamının doğallığını bozmamalıdır. Ders sırasında ögretmenin sağlayacağı ortamdan yararlanarak samimi ve olumlu bir hava içinde öğrencilerin tartışmalarına katılarak, öğrenim durumlarını saptamalidir.

9. Dershanede olumlu bir hava yaratılmalıdır. Müfettiş öğretmenle iletişim kurarak ve katkısını sağlayarak öğrencilerle dershanede konuşmalı ilişki içinde bulunmalıdır. Öğretim konusu ile ilgili ve ,öğrenci seviyesine uygun soruları gruba yönelterek sorucevap yöntemi ile öğretime katılmał, öğrencilerin dersle ilgili görüşleri hakkında bilgi edinmelidir. Öğrenci cevaplarının dikkatle izlenmesi, sorularının cevaplandırılması, uygun bir tartışma ortanmını sağlanması öğretimin geliştirilmesini kolaylaş̧ırır, denetimin önem. ve gereği ile yararı kanıtlanır.

10. Müfettiş dershaneden öğretmenle birlikte ayrılmalıdır. Öğretmenin bir konuda yaptığ öğretimde, derse giriși, işleyişi ve sonunda özetleyişi ile değerlendirmesi gözlenmelidir. Ayrıca ders esnasinda bütünlüğü bozmamak, denetime öğretimi geliştirmede bir süreç olduğunu kanıtlamak için denetimin dersin sonuna kadar sürdürülmesi gerekir.

11. Bir öğretmenin iki veya daha fazla dersi ve sinıfı varsa en àz ikisindeki öğretimi gözlenmelidir. Öğretmenin bir günde ve yalnız bir ders saatinde yaptığı öğretim şekli ile başarısını değerlendirmekle belli bir andaki durumu saptanmış olur. Öğretmenin öğretimdeki başarısını dershanenin fiziki ortamı, öğrenci seviyesi ve sayısı, işlenen konu gibi faktörler de etkiler. Bu bakımdan değişik zaman, yer ve ortamda yapılan değerlendirme daha objektif olur.

12. Ders denetiminde çevre koşulları ve olanakları dikkate alınmahıdır. Öğı encilerin okulda kazandıkları bilgileri uygulama imkanı bulması çevre koşullarına ve bulunduğu ortama bağlıdır. Çevrenin yapıs1, özellikleri ve beklentileri öğrencilerin davranışlarını, dolayısiyle öğretmenin de başarısıını etkiliyecektir. 
13. Ders denetimi sonunda ara vermeden gözlem formu doldurulmalıdır. Müfettişin denetim yaptığı sırada not alması veya formu doldurması öğretmen ve öğrencilerin ilgisini çekecektir. Bu bakımdan dershanede gözlemi eksiksiz olarak yapmalı, öğretimi dikkatle izlemeli, formdaki sorunların cevaplarını verebilecek gözlem sonuclarinı saklı tutmalıdır. Gözlem formu denetimden çok kısa bir zaman sonra doldurulmalıdır. Aksi halde müfettiş gözlem sonuçlarını hatırlama ve puvanlamada güçlük çeker.

14. Ders denetimlerinde ders dı̧̧ etkinlikler de değerlendirilmelidir. Derslerin konuları, okulun amaçlarını gerçekleştirmek üzere öğrencilerde beklenen davranış değiş̧ikliğini oluşturacak bilgi, beceri ve tutumları kapsar. Öğrenciye istenilen davranış salt ders içi etkinliklerle değil, bunun yanısıra, ders ve konuların özelliklerine göre ders dişında yapılacak çalışmalarla kazandırılır. Ayrıca öğretmenin okulda başarılı bir öğretim yapabilmesi için ders dışında bazı çalışmalar yapmasi beklenir. Bu bakımdan ders denetiminden sonra, öğretmenin ders öncesi ve sonrası yaptığı ders dışı etkinlikler de incelenerek form doldurulur.

15. Müfettiş ders denetimi sonunda öğretmenle yalnız görüşmelidir. Ders denetiminden sonra öğretmenle demokratik bir ortamda yapilan görüşmede, öğretmen davranışlarının olumlu ve beğenilen, olumsuz ve beğenilmeyen yönleri açıklanir. Öğretmenin beğenilmiyen davranışlarının biçimi, etken faktörler ve neḍenleri tartışılır, giderilmesi ve geliştirilmesi için mesleki rehberlik yapılır ve yardım edilir.

16. Okuldaki denetim sonunda öğretmen toplantıları düzenlenmelidir. Okul yöneticilerinin de katılabileceği bu toplantılarda. birey olarak öğretmen ismi verilmeksizin, öğretim süreci ile ilgili çeşitli konularda eleştiri yapılmalidır, Eleştiri sırasında iyi ve olumlu yönler ile kötü ve olumsuz yönler açıklanmalı, nedenleri, etken faktörler, geliştirilmesi için önlemler tartışılmalı, önermeli, yol gösterilmeli ve yardım edilmelidir.

\section{Ders Denetimi Gözlem Formu}

Öğretmenin dershane içinde yaptığı çalışmaların planlı olarak gözlenmesi ve gözlem sonuçlarının işlenmesi için hazırlanan form- 
dur. $\mathrm{Bu}$ formlar öğretmenlerin dershane içinde yaptıkları öğretimle ilgili gözlem sonuçlarının aynı ölçeklere göre ve sistemli bir şekilde yazılması ve değerlendirme yapılması için hazırlanır ve kullanılır. Müfettiş, normal koşullarda öğretmenin ders verirken uyması gẹreken genel kuralları ve öğretimdeki becerisi hakkında, önceden kabul edilen bareme göre başarı derecesi saptar ve formdaki hanesine işaret koyar. Konulan işaretin derecesini gösteren sayısal değerlerin toplam ve ortalamaları alınarak gözlem sonu başarı belirlenir. Bu tür formları kullanmanın yararlarından biri, gözlenen bireyin hangi etkinlik veya davranışta başarılı, hangisinde yetersiz olduğu, net olarak görülebilmesidir.

\section{Ders Dışı Etkinliklerin Değerlendirilmesi}

Ders denetimlerinde sadece ders saatlerindeki çalışmaların değerlendirilmesi ile yetinilmiyerek öğretmenin ders dişı etkinliklerininde dikkate alınması gerekir. Ders dışı çalışmalarının değerlendirilmesi için tek bir kaynak ve yöntem yoktur. Öğretmenin bilgi ve becerisinden çok kazandığı alışkanlıkları gözliyerek, hakkında inceleme yapılarak bir hükme varılabilir. Öğretmenin ders dı̧ı etkinliklerinin kolaylıkla değerlendirilmesi için öğretmenin çalışı̆̆ı okul ve alanına göre hazırlanmış formlar kullanılabilir. Örnek olarak verilen gözlem formu, orta dereceleri okulda, öğretmenin ders dişı etkinliklerini gözleme ve değerlendirmede kullanılmak üzere tasarlanmıştır. Taslak halindeki bu form geliştirilebilir.

\section{Kullamılan Ölçekler}

Denetim sonuçlarmun değerlendirilmesi için, sistemde çok kullanılmış, alı̧ıılmış ve benimsenmiş olan aşağıdaki ölçekler kullanılabilir.

$\begin{array}{cl}\frac{\text { Puanlar }}{0} & \frac{\text { Başarı Derecesi }}{\text { Hiç }} \\ 1 & \text { Yetersiz } \\ 2 & \text { Orta } \\ 3 & \text { İyi } \\ 4 & \text { Pekiyi } \\ - & \text { Gözlenemedi }\end{array}$


Denetim yapllırken öğretmenin etkinlikleri a) doğru b) süresi içinde c) aranılan nitelikte d) beklenen davranışı göstererek yapmadaki başarısı saptanır ve form üzerinde işaretlenir. İşaretli puvanların toplamının başarı durumu değerlendirilir. Değerlendirme yapılırken aşağıdaki ölçek aralıkları ve dereceler kullanılır.

Ölçek Aralığı

Başarı Derecesi

0.00-0.79 arasındaki ortalama pavunlar için Yetersiz

$\begin{array}{llllll}1.80-2.59 & " & " & " & " & \text { Orta } \\ 2.60-3.59 & " & , & , & , & \text { İyi } \\ 3.40-4.00 & & , & , & , & \text { Çokiyi }\end{array}$

Denetleme sonuçlarının 100 puan baremine göre değerlendirilmesi istenirse ortalamalar 25 katsayısı ile çarpılır ve aşağıdaki ölçek aralığı ile başarı dereceleri kullanılır.

\begin{tabular}{|c|c|c|c|c|c|}
\hline Ölçek Al & alığ1 & & & & Başarı Derecesi \\
\hline $0-44$ & arasındaki & ortalama & puvanlar & için & Yetersiz \\
\hline $45-64$ & " & $"$ & , & $"$ & Orta \\
\hline $65-84$ & $"$ & $"$ & $"$ & ” & İyi \\
\hline $85-100$ & $\because "$ & $"$ & , & $"$ & Çokiyi \\
\hline
\end{tabular}

Formların altında not başlığı ile boș bırakılan alana gözlem yolu ile yapılan denetimle ilgili olarak açıklanması gerekli görülen hususlar yazılır. Bu formlar aynı veya farklı renklerde üçer adet, aralarına karbon konularak doldurulduğunda makama verilecek formun dışında birincisi müfettişte. kalabilir ve bir kopyası öğretmene verilebilir.

Öğretmenin seçeceği öğretim metodunu belirleyen en önemli unsur, öğretimin amaçları ve prensipleri, sağlanabilen imkanları ve ortạmdır. Her öğretim metodunun uygulanmasinda gözlenecek davranışları farklılı gösterecektir. Bu nedenle ders denetim gözlem formları derslerin özellikleri dikkate alınarak hazırlanmalı ve uygulanmalıdır. Örnek olarak verilen aşağıdaki form, orta dereceli bir okulda genelde bir ders içi etkinliği gözlemek ve değerlendirmek üzere tasarlanmıştır. 'Bu taslak form geliştirilerek her des veya ders grupları için uygulamada kullanılacak formlar hazırlanabilir. 


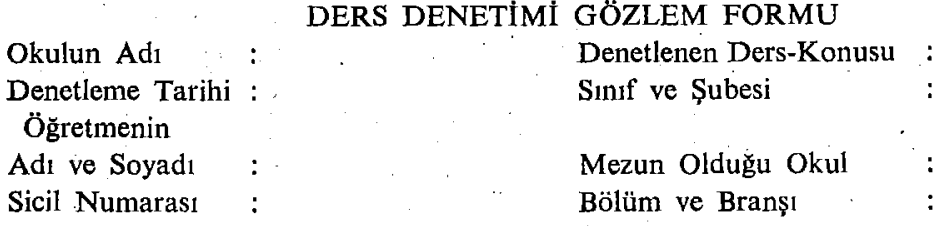

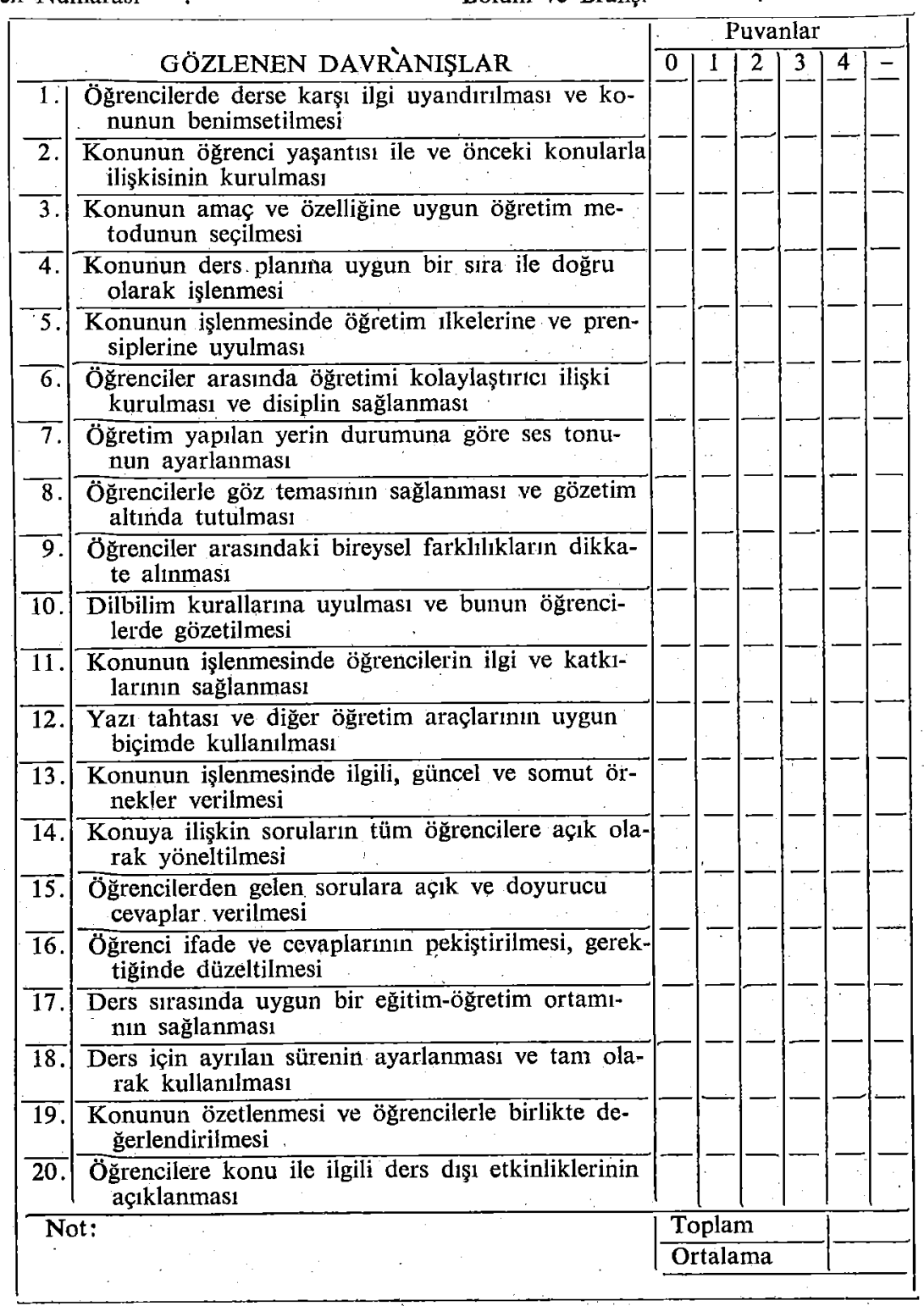




\section{DERS DIŞI ETKINLIIKLERIN DENETIMI GÖZLEM FORMU}

Okulun Ad

Öğretmenin

Adı Soyadı

Sicil Numaras

Haftalık Ders Saati:
Denetleme Tarihi :

Mezun Olduğu Okul :

Bölüm ve Branşı

Okuttuğu Dersler

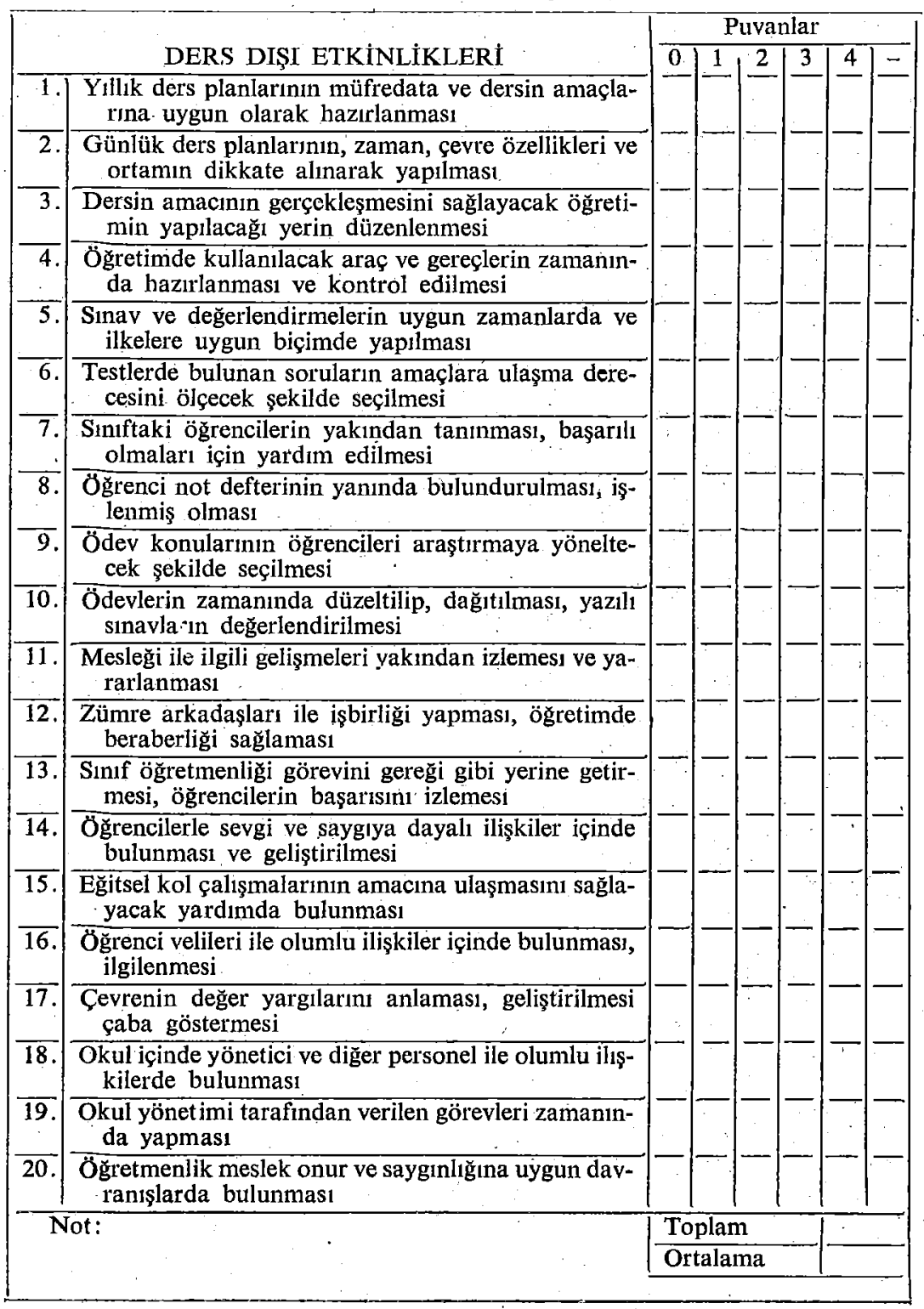




\section{KAYNAKLAR}

Douglas, Harl, R., Bent, Rudyard, K., and Boardman, Charles, W., Democratic Supervision in Secondary Schools, Houghtan Miffin Company, Boston, 1961.

Ergen, Nurettin, Milli Eğitim Bakanlığına Bağh Okullarda Ders Teftişi, Ders Ödevi, Ankara, 1977.

Ficker, Vistor, B., Effective Supervision, Charles E. Merril Publishing Company, Columbus, Ohio, 1975.

Lateiner, Alfred,. Modern Technigues of Supervision, Lateiner Publis hing, Santa Barbara, Ca. 1968.

Milli Eğitim Bakanlı̆̆ı Teftiş Kurulu Başkanlı̆̆ı, Ders Teftişlerinde Dikkate Alınacak Ortak Esaslar, Ankara, 1967 .

Milli Eg̣itim Bakanlığı Teftiş Kurulu Başkanlığı, Ders Teftis Raporlarmm Düzenlenmesi ile ilgili Muhtura, Ankara, 1973.

Poyrazoğlu, O., Nuri, Orta Dereceli Okul Öğretmenlerinin Ders Teftişi Yolu ile Değerle-n dirilmesi, Ders Ödevi, Ankara, 1977.

Senemoğlu, Nuray, Kız Meslek Liselerinde Meslek Derslerinin Teftişi, Ders Ödevi, Ankara, 1981 .

Taymaz, Haydar, Teftis, Kavramlar, Ilkeler, Yöntemler, A.Ü. Eğitim Bilimleri Fakültesi . Yayınları, No: 113, 'Ankara, 1982.

Türkyılmaz, Şevket, Teftiş Tekniği, Gazi Eğitim Enstitüsü Pedogoji Bölümü Ders Notları, Ankara, 1966. 